\title{
An Analysis Of Women Educators In Higher Education And Their Perceptions Of The Use Of Technology In Improving Teacher Effectiveness: A Study In Instructional Technology
}

\author{
Russell Owens, King's College
}

Barbara Fralinger, Rowan University

\begin{abstract}
An understanding of the relationships among the integration of computer technology by women educators in higher education and effective teaching could have a significant impact on education. Pennsylvania Universities and Colleges have made their commitment to educational technology and provided support for the implementation of such technology. Currently, we have little empirical evidence to show that the use of computer technology by women educators actually does improve learning. Incumbent upon this commitment to educational technology, women educators have a right to ask if their investment of time and effort in learning how to use and implement the technology will produce significant benefits for their students. This research developed a survey instrument to rank statements and gain an understanding of the perceptions of women in higher education concerning the integration of computer technology and teacher effectiveness. The methods used to develop the instrument involved the analysis of relevant research, construction of appropriate items, identification of the population sample, validity and reliability, and pilot testing. The population under study was limited to two Colleges and one University in Northeastern Pennsylvania during the spring and fall semesters of 2007. The results indicated that the women surveyed felt teacher effectiveness is most strongly associated with the availability of technology tools to collect data for the purposes of instructional planning. Conversely, participants felt that teacher effectiveness was not strongly associated with lesson sequences that integrate technology resources, implementation of procedures consistent with school policies that protect the privacy of electronic student data, and demonstration of ethical behaviors regarding the use of technology.
\end{abstract}

\section{INTRODUCTION}

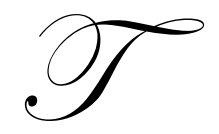

he increase in the hardware and software capabilities of interactive media has facilitated an increase in the use of technology in learning environments (Owens \& Dwyer, 2005). Moreover, a proliferation of computer learning environments is capitalizing on ever-expanding technologies and transforming present learning industries. For a generation of young people, technology, particularly the Internet, has assumed a substantial stake in their social and educational lives. A recent survey conducted by the Pew Internet \& American Life Project (Hitlin \& Rainie, 2005) found that roughly 21 million youth between the ages of 12 and 17 (approximately $87 \%$ of the entire age bracket) use the Internet. Of these 21 million online teens, approximately $78 \%$ (about 16 million students) indicate that they use the Internet at school.

Colleges and universities are requiring teachers to integrate technology-based learning activities into the classroom that promote student engagement in technology. Federal, state, and local agencies are investing billions 
of dollars to equip schools with computers and modern communications networks (Johnson, 1998). An understanding of the relationships among the integration of computer technology and effective teaching could have a significant impact on education. As such, this research sought to gain an understanding of the extent to which implementation of technology increases teacher effectiveness by women in higher education.

\section{LITERATURE REVIEW}

Today's colleges and universities have heavily invested in computers and related technologies, including computer networks, wireless technology, and school homepages. While bombarded with promises of tomorrow's technology, many teachers are struggling to make effective use of today's technologies (Planow, Bauder, Carr, \& Sarner, 1993). Although the integration of all types of technologies into the classroom is viewed as an effective instructional strategy for improving education, many teachers do not have favorable attitudes towards the effectiveness of this technology (Huan, Compley, Williams, \& Waxman, 1992; Padron, 1992). Critics have stated, "We don't need computers in schools. Learning is best done through face-to-face interaction without these technologies (especially in early grades), and we don't need computers to improve education in our schools today" (Carroll, 2000). A recent survey of high school teachers (Law \& Owens, 2006) showed that participating teachers "somewhat agree" with the integration of technology resources into lesson sequences and "agree" with technology resource integration into learning activities. The study revealed that, while there is support for technology resource integration into the curriculum, technology is still not universally accepted as an instrument in the learning process.

O'Dwyer, Russell, Bebell, and Tucker-Seeley (2005), however, found that the use of technology was associated with higher test scores in language arts. Their research, which controlled for prior achievement and socioeconomic status, found that fourth-grade students who reported greater use of technology at school to edit papers were more likely to have higher total English/language arts test and writing scores on the Massachusetts Comprehensive Assessment System.

According to a report based on a 2000 survey conducted by the International Society for Technology in Education (2001) released at the annual conference of the American Association of Colleges for Teacher Education, most teacher-training programs fail to show their students how to incorporate technology into their classroom instruction. The researchers surveyed teacher-education programs across the United States in 2005 and gathered responses from 416 institutions about the extent to which future teachers are being exposed to technology in their classes, clinical experience, and curricular materials.

While most of the institutions reported that they had adequate computers and facilities for technology, most of the faculty members who responded to the survey did not use information technology in their own teaching. The institutions noted, however, that in recent years access to technology had increased faster than technology had been incorporated into teaching and learning. As such, ongoing professional development is necessary to help teachers learn not only how to use new technology, but also how to provide meaningful instruction and activities using technology in the classroom (Ringstaff \& Kelley, 2002). Owens and Fralinger (2007) found that technology in education incorporating a student designed and developed computer-based tutorial increased student perceptions of academic learning.

The fundamental error in the implementation of computer technology is that typically, no one asks women educators how this technology might serve their instructional methods or contribute to better learning by their students; teachers are simply told to get on the bandwagon. Ideally, the teachers themselves would make decisions about whether and to what extent they and their institutions should invest time and money in technology.

If we assume that women educators, on the whole, know how to teach and are reasonably successful in this enterprise, can we not also assume that they are capable of judging whether a new method or new technology will help or hinder them? Most faculty members are slow to adopt new technology simply because they are not convinced that using it will improve their students' learning (Rosen \& Weil, 1995, p. 10). 


\section{PURPOSE OF THE STUDY}

The purpose of this study was to understand the perceived relationships among the integration of computer technology by women educators in higher education and effective teaching.

\section{SIGNIFICANCE OF THE STUDY}

Currently, women educators have little empirical evidence to show that using computer technology actually improves learning. Incumbent upon this commitment to educational technology, women educators have a right to ask whether their investment of time and effort in learning how to use and implement technology will produce significant benefits for their students. An understanding of the perceived relationships between the integration of computer technology by women in higher education and effective teaching could have a significant impact on education.

\section{SURVEY POPULATION}

The population under study was limited to two Colleges and one University in Northeastern Pennsylvania during the spring and fall semesters of 2007.

\section{METHODOLOGY}

To address the purpose of the study, a survey instrument was developed by the researchers (see APPENDIX A). The methods used to develop the instrument involved the review of relevant research, construction of appropriate items, identification of the population sample, and validity and reliability testing of the instrument. Twenty-one technology standards from The International Society for Technology in Education National Educational Technology Standards (2001) and five categories of teaching effectiveness characteristics (Hildebrand, Wilson, \& Dienst, 1971) guided the development of the nine technology standards and subsequently yielded 16 questions. The International Society for Technology in Education National Educational Technology Standards 2001 project constructs were used as a template for the survey instrument and the selected levels of technology standards. These constructs were modified to combine like concepts to shorten the survey instrument from 21 technology standards to 9 technology standards and combined 5 teacher effectiveness constructs as classified according to a scheme worked out by M. Hildebrand. The first section of the survey instrument contained sixteen questions based on the respondents' perceptions of whether or not the integration of the latest advancements in computer technology by women in higher education increases their effectiveness as a teacher. Respondents were asked to indicate their responses to the survey items using a 7-point Likert-type scale. The number 1 indicates that the respondent strongly disagrees; the number 7 indicates the respondent strongly agrees. The second section contained questions based on college and university practices. For this study, computer technology is defined as the latest advancements in computers and electronics, and their effects on the social and political environment and consequences created by such machines.

The 9 selected levels of technology standards are as follows:

Element \#1: TECHNOLOGY RESOURCE INTEGRATION (questions 1, 2)

Element \#2: TECHNOLOGY RESOURCES (questions 3, 4)

Element \#3: VALIDITY and RELIABILITY of INFORMATION (questions 5, 6)

Element \#4: TELECOMMUNICATIONS (questions 7, 8)

Element \#5: TECHNOLOGY INTERACTION (questions 9, 10)

Element \#6: TECHNOLOGY TOOLS (question 11) 
Element \#7: TECHNOLOGY-BASED COLLABORATION (questions 12)

Element\#8: TECHNOLOGY-RELATED POLICIES (questions 13, 14)

Element\#9: LEGAL AND ETHICAL ISSUES (questions 15, 16)

To increase response rate to the data collection instrument, some step-by-step activities suggested by Dillman in the Total Design Method were applied in the data collection phase. These activities included a cover letter (APPENDIX C) drafted with five objectives: (a) explain the study's usefulness, (b) explain the extent of the study, (c) identify the importance of the respondent to the study, (d) disclose the identification system, (e) express appreciation for participation.

\section{Survey Internal Reliability Pilot Test (n=22)}

Internal consistency estimates of reliability were computed for each of the sixteen constructs: coefficient alpha and split-half coefficient expressed as a Spearman-Bowman reliability coefficient. Alpha coefficient ranges in value from 0 to 1 and may be used to describe the reliability of factors extracted from dichotomous (that is, questions with two possible answers) and/or multi-point formatted questionnaires or scales (i.e., rating scale: $1=$ poor, $5=$ excellent). The higher the score, the more reliable the generated scale. Nunnaly (1978) has indicated 0.7 to be an acceptable reliability coefficient but lower thresholds are sometimes used in the literature. Section one survey questions used the split-half coefficient, splitting the scale into two halves such that the two halves would be as equivalent as possible. The first half included the even-numbered survey items and the second half the oddnumbered survey items. The Cronbach's alpha describes how well the questions asked are related. All values in the survey were over .80 . (The alpha $=0.8921$ with the Standardized item alpha $=.8982$ ). A value over .80 is an acceptable level for a cognitive scale, according to Aiken (1999, p.76).

\section{Data Analysis}

Data obtained from each of the 44 completed surveys were coded and entered into the Statistical Package for Social Sciences (SPSS 9.0) computer software program. The distribution of the data was examined to determine which statistical methods would be most appropriate for assessing the perceptions of women in higher education concerning the integration of computer technology and teacher effectiveness.

\section{DESCRIPTIVE STATISTICS}

Data analysis included primarily descriptive statistics. Descriptive statistics are procedures used for classifying and summarizing, or describing, numerical data (Hinkle, Wiersma, \& Jurs, 1998). By using descriptive statistics, one is able to describe distributions and individual scores, and determine the relationship between variables (Hinkle, Wiersma, \& Jurs, 1998). In this study, descriptive statistics including frequencies, means, medians, modes and standard deviations were calculated and used to examine trends in the Likert Scale scores for the questions presented in the survey to the women educators.

\section{FINDINGS}

\section{Study Sample}

The study sample consisted of 44 subjects. Each subject was a female college professor. Administration of the survey was done at each site, with the researchers present for survey distribution. This method of administration was used to ensure $100 \%$ survey completion by the subjects. 


\section{Analysis Of The Data}

The data obtained in this study were analyzed using primarily descriptive statistics including frequencies, means, medians, modes, and standard deviations. The relationships between the sixteen questions (based on the nine technology standards) presented and the seven levels of agreement were primarily analyzed using quantitative analyses. Specifically, the researchers examined participant perceptions of whether the use of the nine technology standards increased teacher effectiveness.

\section{Coding System}

The first 16 questions of the survey assessed the association between the nine technology standards and teacher effectiveness. Questions were scored on a 7-point Likert Scale, with 1 representing a "Strongly Disagree" response and 7 indicating a "Strongly Agree" response. Questions 17-20 assessed participant knowledge of institutional technology resources; responses for these questions as well as the 5 questions assessing the clarity and content of the questionnaire were treated as dichotomous "yes/no" variables $(1=$ Yes; $0=\mathrm{No})$, with the third option of "Don't know/Refuse" treated as a missing variable.

\section{Frequency Distributions}

As noted above, the purpose of this study was to understand the perceptions of women in higher education concerning the relationship among the integration of computer technology in higher education and effective teaching. Specifically, the researchers examined whether the use of nine technology standards increased perceptions of teacher effectiveness. Frequency distributions for the sixteen questions are presented in Appendix D. Frequencies were calculated to determine the mean score for each issue and also to see if the data were normally distributed. The mean score represents the average ranking given by respondents for each question. The mean scores and frequency distributions were used to determine with which statements respondents most strongly agreed. Results indicated that of the 16 questions concerning teacher effectiveness, respondents most strongly agreed with the statements presented in questions 5, 6, 8, and 11; questions 1, 13, and 15 received the lowest rankings, as average responses were primarily between "neutral" and "agree". Figures 1 through 7 show the frequency of participant responses for these questions, respectively.

Figure 1 represents question \#5 (teacher effectiveness is associated with strategies to assess the validity of information gathered through technological means). This question reflects the technology standard VALIDITY and RELIABILITY of INFORMATION. Responses for this question yielded a mean score of 5.5, indicating an average ranking between "agree" and "strongly agree." The standard deviation was 1.19 , signifying that responses to this question had little variability around the mean. In examining the frequency distribution, one can see that the data is not normally distributed. Out of 44 respondents, more than half gave this question a ranking of 5, 6, or 7 . Thus, the majority of respondents strongly agreed with the statement that teacher effectiveness is associated with strategies to assess the validity of information gathered through technological means. 


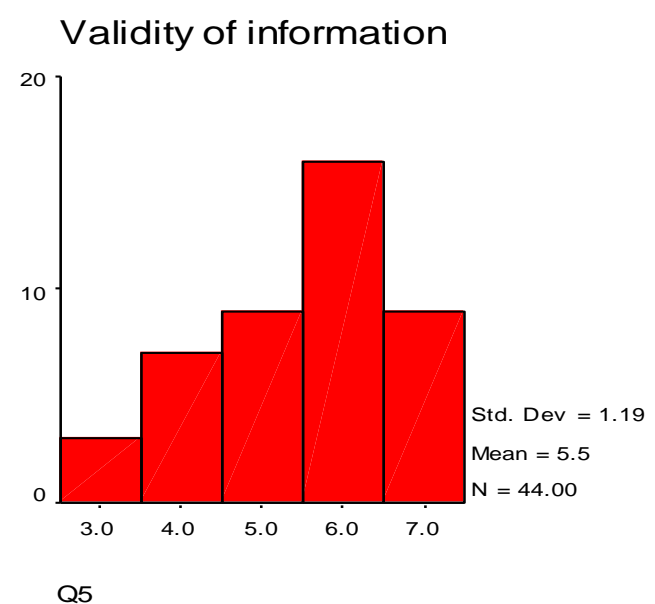

Figure 1: Validity of information.

The mean score was 5.5 and the standard deviation was 1.19, indicating an average response of "agree" to "strongly agree".

Figure 2 represents question \# 6 (teacher effectiveness is associated with strategies to assess the reliability of information gathered through technological means). This question reflects the technology standard VALIDITY and RELIABILITY of INFORMATION. Responses for this question yielded a mean score of 5.5, indicating an average ranking between "agree" and "strongly agree." The standard deviation was 1.09 , signifying that responses to this question had little variability around the mean. In examining the frequency distribution, one can see that the data is not normally distributed. Out of 44 respondents, more than half gave this question a ranking of 5, 6, or 7, with 6 being the most frequently occurring score. Thus, the majority of respondents strongly agreed with the statement that teacher effectiveness is associated with strategies to assess the reliability of information gathered through technological means.

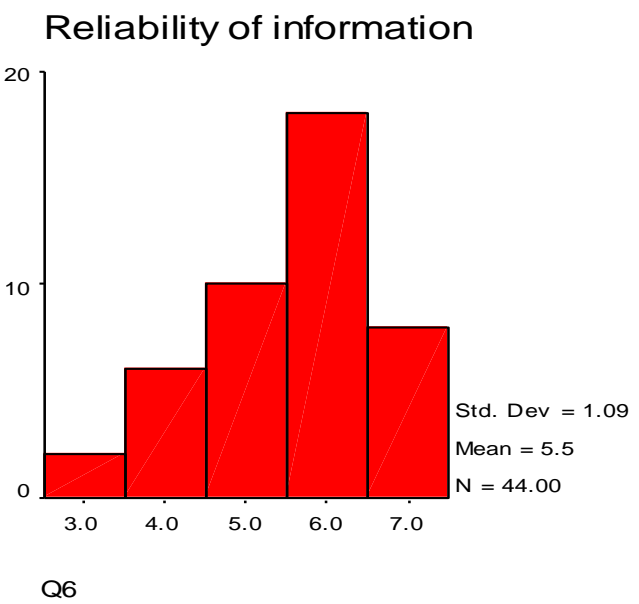

Figure 2: Reliability of information.

The mean score was 5.5 and the standard deviation was 1.09, indicating an average response of "agree" to "strongly agree".

Figure 3 represents question \#8 (teacher effectiveness is associated with providing students with the opportunity to share their talents in the use of technology expertise with others). This question reflects the technology standard TELECOMMUNICATIONS. Responses for this question yielded a mean score of 5.5, 
indicating an average ranking between "agree" and "strongly agree." The standard deviation was 1.49 , signifying that responses to this question had little variability around the mean. In examining the frequency distribution, one can see that the data is not normally distributed. Out of 44 respondents, more than half gave this question a ranking of 5,6 , or 7 . Thus, the majority of respondents strongly agreed with the statement that teacher effectiveness is associated with providing students with the opportunity to share their talents in the use of technology expertise with others.

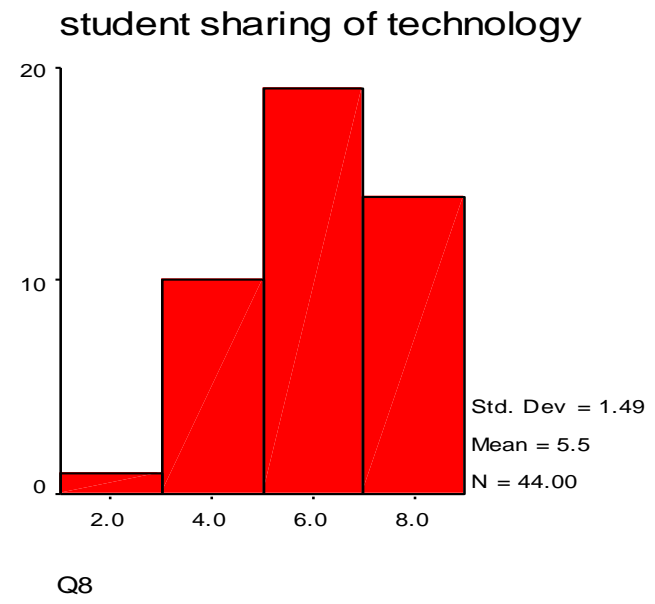

Figure 3: Student sharing of technology.

The mean score was 5.5 and the standard deviation was 1.49, indicating an average response of "agree" to "strongly agree".

Figure 4 represents question \# 11 (teacher effectiveness is associated with technology tools to collect data for the purposes of instructional planning). This question reflects the technology standard TECHNOLOGY TOOLS. Responses for this question yielded a mean score of 5.6, indicating an average ranking between "agree" and "strongly agree." The standard deviation was 1.37 , signifying that responses to this question had little variability around the mean. In examining the frequency distribution, one can see that the data is not normally distributed. Out of 44 respondents, more than half gave this question a ranking of 5,6, or 7. Thus, the majority of respondents strongly agreed with the statement that teacher effectiveness is associated with technology tools to collect data for the purposes of instructional planning.
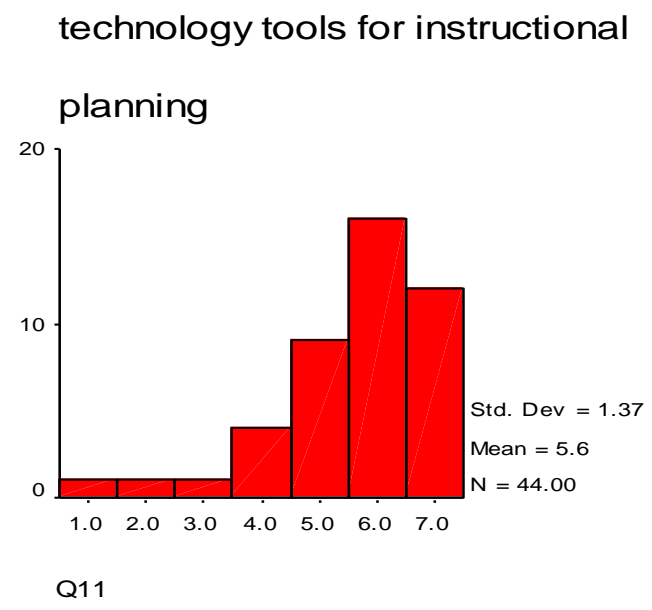

Figure 4: Technology tools for instructional planning.

The mean score was 5.6 and the standard deviation was 1.37 , indicating an average response of "agree" to "strongly agree". 
Figure 5 represents question \#1 (teacher effectiveness is associated with lesson sequences that integrate technology resources). This question reflects the technology standard TECHNOLOGY RESOURCE INTEGRATION. Responses for this question yielded a mean score of 4.6, indicating an average ranking between "neutral" and "agree". The standard deviation was 1.53, signifying that responses to this question had little variability around the mean. In examining the frequency distribution, one can see that the data is not normally distributed. Out of 44 respondents, most gave this question a ranking of either 4 or 5 . Thus, the majority of respondents neither strongly agreed nor disagreed with the statement that teacher effectiveness is associated with lesson sequences that integrate technology resources.

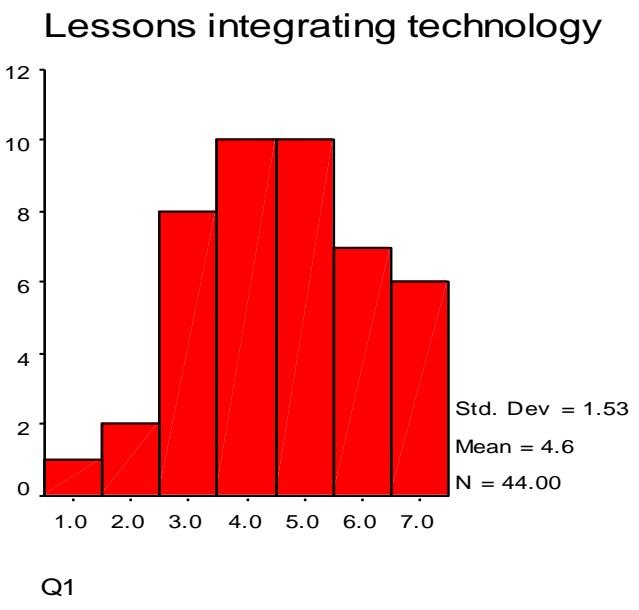

Figure 5: Lessons integrating technology.

The mean score was 4.6 and the standard deviation was 1.53, indicating an average response between "neutral" and "agree".

Figure 6 represents question \#13 (teacher effectiveness is associated with implementing procedures consistent with school policies that protect the privacy of electronic student data). This question reflects the technology standard TECHNOLOGY RELATED POLICIES. Responses for this question yielded a mean score of 4.8 , indicating an average ranking between "neutral" and "agree". The standard deviation was 1.45 , signifying that responses to this question had little variability around the mean. In examining the frequency distribution, one can see that the data is not normally distributed. Out of 44 respondents, most gave this question a ranking of either 4 or 5. Thus, the majority of respondents neither strongly agreed nor disagreed with the statement that teacher effectiveness is associated with implementing procedures consistent with school policies that protect the privacy of electronic student data. 


\section{protecting electronic data}

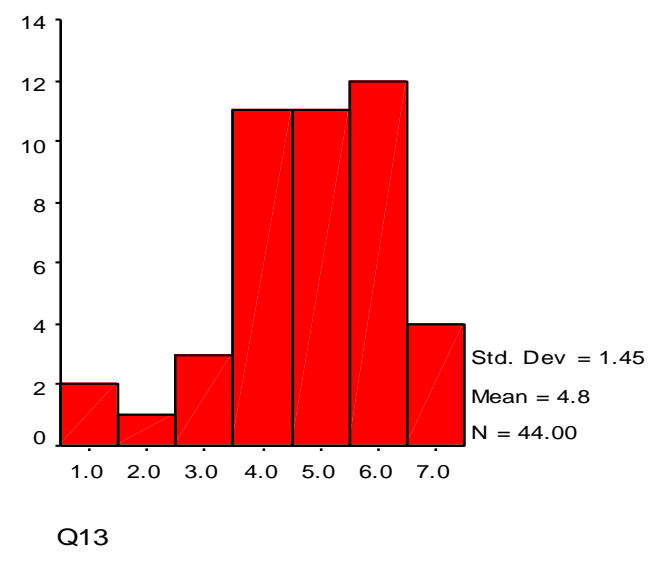

Figure 6: Protecting electronic data.

The mean score was 4.8 and the standard deviation was 1.45 , indicating an average response of between "neutral" and "agree".

Figure 7 represents question \#15 (teacher effectiveness is associated with demonstrating ethical behaviors regarding the use of technology). This question reflects the technology standard LEGAL AND ETHICAL ISSUES. Responses for this question yielded a mean score of 4.9, indicating an average ranking between "neutral" and "agree". The standard deviation was 1.53 , signifying that responses to this question had little variability around the mean. In examining the frequency distribution, one can see that the data is not normally distributed. Out of 44 respondents, most gave this question a ranking between 4 and 6 . Thus, the majority of respondents neither strongly agreed nor disagreed with the statement that teacher effectiveness is associated with demonstrating ethical behaviors regarding the use of technology.

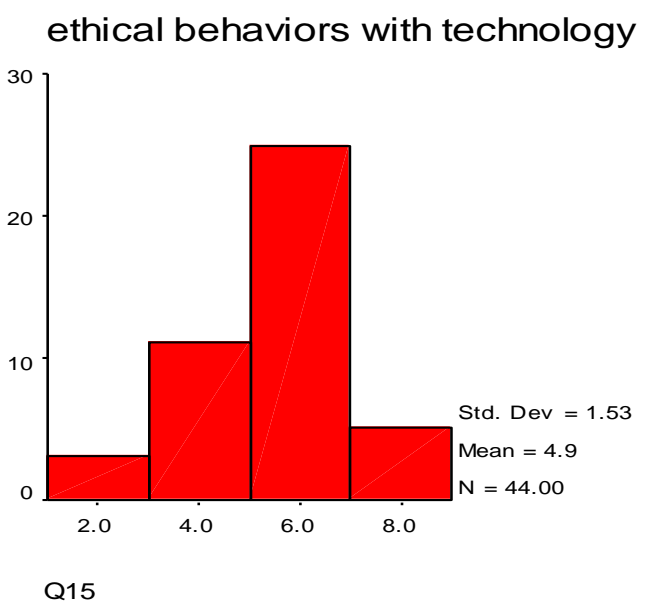

Figure 7: Ethical behaviors with technology.

The mean score was 4.9 and the standard deviation was 1.53, indicating an average response between "neutral" and "agree". 


\section{CONCLUSIONS}

In this study, we concluded that the women surveyed felt that teacher effectiveness is most strongly associated with the availability of technology tools to collect data for the purposes of instructional planning. Respondents also agreed that teacher effectiveness is associated with strategies to assess both the validity and reliability of information gathered through technological means as well as provision of student opportunities to share their talents in the use of technology expertise with others. The statements that received the lowest rankings were those with which respondents did not particularly agree or disagree; these include the statements that teacher effectiveness is associated with lesson sequences that integrate technology resources, implementation of procedures consistent with school policies that protect the privacy of electronic student data, and demonstration of ethical behaviors regarding the use of technology. Results indicated that of the 16 questions concerning teacher effectiveness, respondents most strongly agreed with the statements presented in questions 5, 6, 8, and 11; questions 1,13 , and 15 received the lowest rankings, as average responses were primarily between "neutral" and "agree".

This study has substantiated the need for further research regarding technology use by women in higher education as well as the incorporation of more technology tools for better instructional planning. Through increased technology availability and learning, women in higher education will be more encouraged to engage their students academically using the most current tools to date.

\section{RECOMMENDATIONS}

This study identified the perceptions of women educators in higher education concerning the relationship of technology usage and teacher effectiveness. The results strongly validate the need for further study on this topic. Future research may involve surveying the perceptions of women educators at a variety of higher education institutions throughout the country in order to increase the generalizability of the results found in this study.

Women educators require a valid scientific knowledge base if they are to effectively teach their students using the most current technology available. This knowledge base currently does not exist and in part accounts for why this study was primarily descriptive. The responses of the women educators in this study to the survey items presented have provided some of the first scientific data on the perceptions of women in higher education regarding the relationship of technology usage in the classroom and teacher effectiveness. The present study did not examine women educators outside of the state of Pennsylvania. By broadening the scope of the current study to include schools from different areas of the United States, one can obtain a more collective view on the perceptions of women educators regarding technology use and teacher effectiveness.

\section{REFERENCES}

1. Carroll, T. G. (2000). If we didn't have the schools we have today, would we create the schools we have today? Contemporary Issues in Technology and Teacher Education [Online serial], 1(1). Retrieved on December, 2005 from: http://www.citejournal.org/vol1/iss1/currentissues/general/article1.htm

2. Hildebrand, M., Wilson, R. C., \& Dienst, E. R. (1971). Evaluating university teaching. Berkeley: University of California, Center for Research and Development in Higher Education, 1971).

3. Hitlin, P. \& Rainie, L. (2005, August). Teens, technology, and school. Data memo. Washington,DC: Pew Internet \& American Life Project.

4. Huan, S, Compley, R., Williams, B., \& Waxman, A. (1992). Investigating middle school mathematics teachers' attitudes toward calculator use. Retrieved on December, 2005 from: www.ischool.utexas.edu/ $\sim$ wyllys/SAEMaterials/SAMS Report.pdf

5. International Society for Technology in Education (ISTE) NETS for Teachers Project, U.S. Department of Education, Preparing Tomorrow's Teachers to Use Technology (2001). Retrieved June 5, 2001, from http://cnets.iste.org/index 3. html

6. Law, M.D., Owens, R. K., (2006, April). The Perceptions of the Integration of Information Technology on Teacher Effectiveness. Presented at the $17^{\text {th }}$ International Conference on College teaching and learning, Vedra beach, Florida. 
7. O’Dwyer, L.M., Russell, M., Bebell, D., \& Tucker-Seeley, K.R. (2005, January). Examining the relationship between home and school computer use and students' English/Language Arts test scores. The Journal of Technology, Learning, and Assessment, 3(3), 30-41.

8. Owens, R.K., Dwyer, F.M., (2005). The Effects of Varied Cueing Strategies in Complementing Animated Visual Imagery in Facilitating Achievement of Different Educational Objectives. International Journal of Instructional Media, Vol. 32, Number 4, 2005.

9. Owens, R.K., Fralinger, B., (2006). Computer-Based Student Created Tutorials as a learning Tool. 2006 IBER \& TLC Conference Proceedings.

10. Planow, M., Bauder, D., Carr, D., \& Sarrar, R. (1993). Structuring teachers' attitudinal changes: A follow up study. Technology and Teacher Education Annual: Association for the Advancement of Computing in Education.

11. Ringstaff, C., \& Kelley, L. (2002). The learning return on our educational technology investment. San Francisco: Wasted.

12. Rosen, L., \& Weil, M. M. (1995). Computer availability, computer experience and technophobia among public school teachers. Computers in Human Behavior, 11, 9-31.

Direct Reprint Requests to:

Dr Russell Owens

Assistant Professor of Education

King's College

133 North River street

Wilkes-Barre, PA 18711

Email russellowens@kings.edu

Phone 570-208-5900 ext-5772

Administration Building RM 206 
NOTES 